DOI: 10.20472/IAC.2018.036.029

DAVID MEREDITH

Webster University, , Thailand

\title{
EXPLORING THE INFLUENTIAL FACTORS IN PERCEIVED VALUE OF LINE: ENJOYMENT OF LINE ACTIVITY, PERCEIVED RISK, AND PRIVACY CONCERN OF LINE USERS IN BANGKOK
}

\begin{abstract}
:
The purpose of this research was to explore the influential factors in the perceived value of the users of the LINE application in Bangkok, Thailand. The research model consisted of four latent variables: privacy concern (PC), perceived risk (PR), enjoyment of LINE activities (ELA) and perceived value of LINE (PVL). The data was collected from a sample of 190 respondents all of whom used the LINE application. The research instrument was a survey questionnaire using a five-point Likert scale for measuring respondent's attitudes. Data was analyzed using the SPSS programme and SmartPLS version 2.0.M3 programme. The findings revealed that LINE application users' ELA influences PVL, while ELA is not influenced by PC and PR. This study also confirms that LINE application users' PR is significantly associated with PC. These findings can help managers and decision makers of the LINE application to keep apace with research on consumer attitudes and to make suitable and appropriate developments in the functions of LINE. Additionally, it will assist LINE managers in developing suitable strategies to achieve competitive advantage.
\end{abstract}

\section{Keywords:}

Enjoyment of LINE activity, LINE application, perceived risk, perceived value of LINE, privacy concern

JEL Classification: 125 


\section{Introduction}

LINE, a social mobile App, is changing the way in which people communicate and maintain relationships with others. It offers free messaging capabilities and is helpful for users to instantly connect with their friends. According to a recent report from LINE's Managing Director (MD) of Thailand, LINE's profitability growth increased $40 \%$ in 2014 and made profits of around one billion US dollars in 2015. The popularity of LINE is demonstrated by the 33 million Thai users. LINE is now only second, in terms of application usage in Thailand, to Facebook. LINE has gained popularity, not only as a result of the real-time nature of messaging, but also the many free functions it provides users. For example, new friends can be easily added by scanning a QR code, adding an identification code or simply by two new friends, who are both existing LINE users, standing next to each other and shaking their phones. If friends want to know where another one is located then there is a feature that allows them to share their location. Not only is it easy to join, but users can send emoticons, stickers, photographs, video clips, documents, make free voice or video calls, use the application on a computer and chat in groups.

Such an array of easy to use features in applications such as LINE, WeChat, Instagram and others have reduced the previous predominance of Facebook, which has suffered because users have concerns about privacy, (Hsiao, Chang, \& Tang, 2016). As more developers launch new social Apps, users have increasing alternatives and can easily switch between apps that they consider offer them the best features or ease of use. So, whilst it is a considerable achievement for companies such as LINE to catch 33 million users in Thailand, perhaps the bigger challenge is how to hold onto those users in the face of tough competition from other exiting social media apps and the potential horde of new and, as yet, unknown upstarts. The following four issues are raised in this study: (1) how users perceived the value and risk attached to using LINE; (2) users concerns about the privacy of using LINE; (3) users enjoyment in using LINE and (4) the major factors influencing users perceived value of LINE.

Previous research on social media applications reveals that there are both positive and negative relationships between the four constructs. The two positive relationships are between: (1) privacy concerns and perceived risk (Ofori, Larbi-Siaw, Fianu, Gladjah, \& Boateng 2015; Slyke, Shim, Johnson, \& Jiang, 2006; Zhou \& Li, 2014); and (2) the enjoyment of LINE and perceived value of LINE (Chang, Shen, \& Liu, 2016; Fagan, Neill, \& Wooldridge, 2008; Lee, Chung, \& Lee, 2013; Venkatesh, 2000; Venkatesh, Morris, Davis, \& Davis., 2003; Venkatesh, Thong, \& Xu, 2012). The negative relationship is between privacy concers and the enjoyment of using LINE (Chang et al., 2016). 
Previous research on applications such as LINE is quite limited. Van De Bogart and Wichadee's (2015) research on users intentions adopted the Technology Acceptance Model' (TAM) and found that perceived usefulness and attitude toward usage had a positive relationship with intention to use. Additionally, the perceived ease of use was positively related to perceived usefulness. On the other hand, Van De Bogart and Wichadee (2015) found no relationship between perceived ease of use and attitude toward usage. Research by Hsiao et al. (2016) explored the factors that influenced the continued use of social media applications. They identified three areas: (1) the users' satisfaction; (2) the extent they could connect and network with others; and (3) the pleasure and enjoyment gained by using the application. Additionally, satisfaction and habit had a mediating effect between perceived usefulness and intention to continue using an application.

The limited previous research about LINE reveals a gap in that little or no research has been done to explore the influential factors in the perceived value of the LINE. Thus, this study explores the critical factors that affect LINE users' perceptions from the perspective of privacy concerns, perceived risk, enjoyment of LINE activity and perceived value of LINE. This research is useful in that it will increase knowledge of the perceived value of LINE.

\section{Literature Review}

\section{LINE}

Since its launch in 2011, the Japanese free mobile messaging and voice calls application LINE has grown phenomenally with 400 million registered users by $1^{\text {st }}$ April 2014 (LINE, 2014) in 230 countries, (China Economic Review, 2013). It is the leading messaging application in Japan (Reyburn, 2013) and in Thailand it is also the application of choice (Purnell, 2014). LINE can be used for instant messaging on devices such as smart phones, tablets and even desk top computers. Users can form groups, send messages, photographs, videos and stickers in a spontaneous and informal exchange of ideas (Meredith, 2017).

\section{Privacy Concern $(P C)$}

The collection and protection of their personal information is a sensitive issue for many instant messaging users and how diligently they feel the company protects and takes care of their data is the prime issue involved in 'Privacy Concern' (Chang, Liu, \& Lin, 2015; Nofer, Hinz, Muntermann, \& Roßnagel, 2014). PC is characterized by issues such 
as data being collected or accessed without the user's knowledge or permission, errors in the storage or safety of data and the company's awareness and sensitive to the issue of the privacy of user's data (Malhotra, Kim, \& Agarwal, 2004). Consumers become concerned when they perceive that their private, personal information is at risk, they are unsure about who will have access, how data will be used and the safety and security of their storage (Dinev \& Hart, 2006a; Dinev \& Hart, 2006b; Xu, Dinev, Smith, \& Hart, 2011). Prior studies discovered that PC had a positive effect on perceived risk (PR) (Slyke et al., 2006; Zhou \& Li, 2014; Ofori et al., 2015), but negatively affected the enjoyment of smartphone social networking services (SNS) activity. PC also had an indirect effect on perceived value (PV) through enjoyment of smartphone SNS (Chang et al., 2016).

H1. Privacy concern about LINE positively affects perceived risk.

H2. Privacy concern about LINE negatively affects enjoyment of LINE activity.

\section{Perceived Risk (PR)}

The consumer will have a perception of risk (PR) if they have uncertainty of the adverse consequences of conducting an activity or behaviour (Dowling \& Staelin, 1994). Sheppard and Sherman ((1998) found that the various risks associated with relationships can result in inaction or lead to feelings of engulfment, dread, or anxiety. Prior research shows that PR positively affects enjoyment of SNS activity and perceived PV (Chang et al., 2016).

H3. Perceived risk positively affects the enjoyment of LINE activity.

H4. Perceived risk positively affects perceived value of LINE.

\section{Enjoyment of LINE Activity (ELA) and Perceived Value of LINE (PVL)}

Huang, Lin, and Chuang (2007) detail how using technology might involve activities that are enjoyable regardless of whatever the purpose or expected outcome of that use might be. Zeithaml (1988) described how the perceived value of a product or service is concerned with how a user might assess what they receive or give. There are researchers who offer similar definitions of PVL as the benefits a customer receives or the sacrifices they might make (Dodds, Monroe, \& Grewal, 1991; Teas \& Agarwal, 2000; Zeithaml, 1988). Dodds et al. (1991) and Zeithaml (1988) detail how benefits relate to the perceptions of a customer. Such benefits are characterized by the customer's assessment of the quality of a service and the potential for their economic or social benefits. Sacrifices are characterized by time, effort, convenience, risk and financial outlay. 
When a user has an perception of enjoyment that can, in turn, result in a positive value perception (Fagan et al., 2008; Venkatesh, 2000; Venkatesh et al., 2003). The important role of perceived enjoyment is when it connects with perceived value, as together they form a pleasure-orientated information system environment (Lee et al., 2013; Venkatesh et al., 2012). Chang et al. (2016) found that enjoyment of social network services activity positively affects perceived value.

H5. Enjoyment of LINE activity positively affects perceived value of LINE.

Figure 1: Conceptual Framework

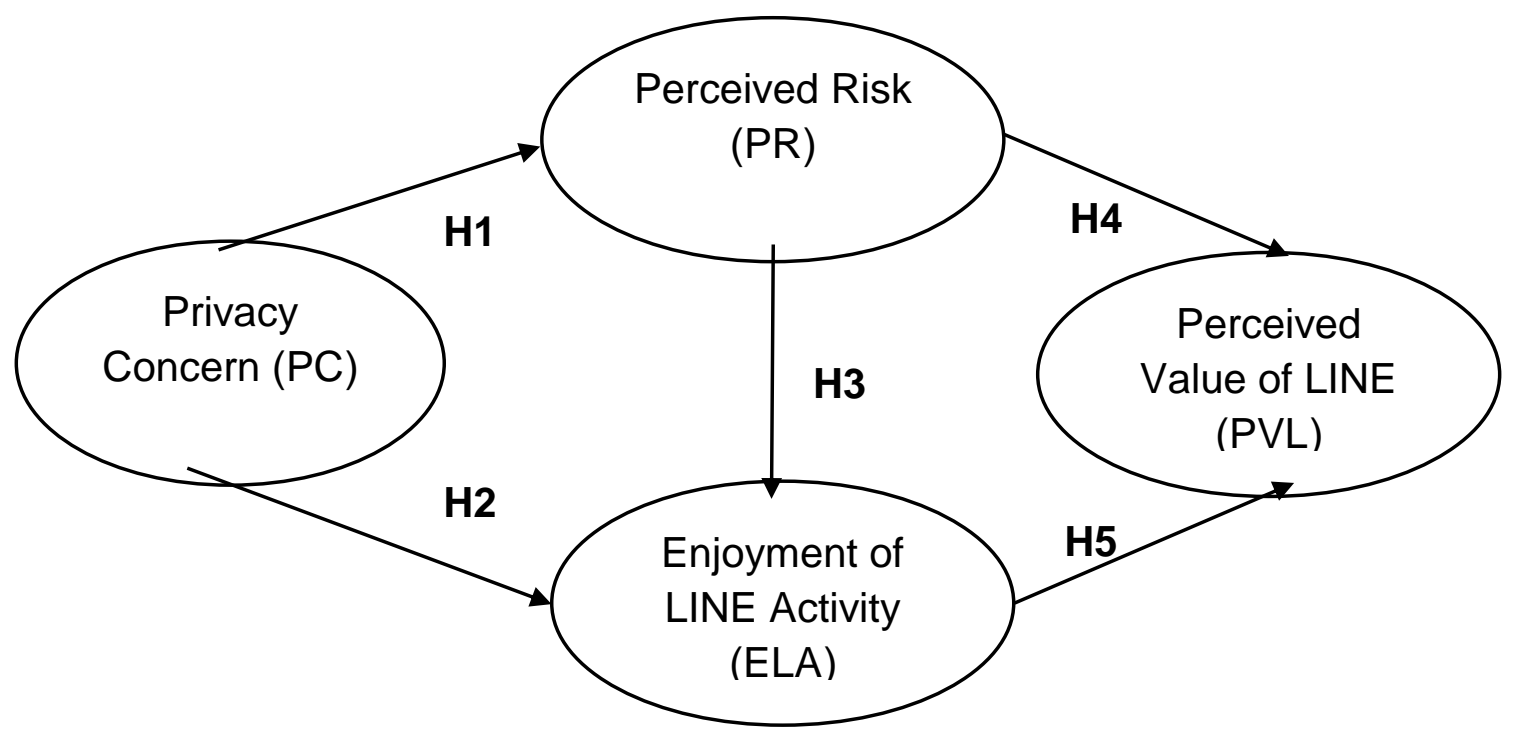

\section{Research Methodology}

A questionnaire was developed in order to ascertain the PV of the customers who use the LINE application. The results of a review of the relevant literature and in-depth interviews with twelve users of the LINE application were utilized to ensure the content validity of the survey tool. Each item on the questionnaire used a five point Likert scale ranging from 15 or strongly disagree to strongly agree. These were tested on a small pilot group of thirty students. The purpose of the pilot was to ascertain if the questions could be easily understood using cronbach's alpha and exploratory factor analysis. Once the pilot was complete the prototype questionnaire was modified by removing items that did not load on a factor appropriately. The final version of the questionnaire comprised of twenty-two items (Table 1), which related to four constructs. This broke-down into PC (5 items), PR (6 items), ELA (6 items), and PVL (5 items). 
Table 1: Questionnaire Items and Their Derivation Sources

\begin{tabular}{|c|c|c|}
\hline Item & Description & Source \\
\hline \multicolumn{3}{|c|}{ Privacy Concerns (PC) } \\
\hline PC1 & I am concerned that my personal data may be read by other people. & \multirow{4}{*}{$\begin{array}{l}\text { Chang et al. } \\
(2016) ; \text { Shin } \\
(2010) ; \text { Tan and } \\
\text { Qin (2012) }\end{array}$} \\
\hline PC2 & I am concerned that my personal data may be used by other people. & \\
\hline PC3 & $\begin{array}{l}\text { I am concerned that my personal information on the web will be } \\
\text { accessed and used by other people without my consent. }\end{array}$ & \\
\hline PC4 & I am concerned that using the internet will reveal my privacy information. & \\
\hline PC5 & $\begin{array}{l}\text { The word "Read" which appears in front of text makes me feel like I lack } \\
\text { of privacy, especially when I have read other people texts and I did not } \\
\text { response so that they well know that I intent not to response. }\end{array}$ & Depth interview \\
\hline \multicolumn{3}{|c|}{ Perceived Risk (PR) } \\
\hline PR1 & $\begin{array}{l}\text { The security mechanism provided by the social networking services } \\
\text { (SNS) is not enough to protect my privacy well. }\end{array}$ & \multirow{3}{*}{$\begin{array}{l}\text { Chang et al. } \\
(2016) ; \\
\text { McKnight, } \\
\text { Choudhury, and } \\
\text { Kacmar (2002) }\end{array}$} \\
\hline PR2 & Overall, I think it is more-or-less unsafe to use SNS. & \\
\hline PR3 & I feel that using SNS sometimes may cause unexpected issues. & \\
\hline PR4 & $\begin{array}{l}\text { I feel free call by LINE, its signal is not clear, and the conversation does } \\
\text { not go smoothly. }\end{array}$ & \multirow{3}{*}{ Depth interview } \\
\hline PR5 & $\begin{array}{l}\text { I feel tension in daily life if I do not follow up Group LINE. I am afraid that } \\
\text { I cannot catch up important news from there. Hence, it is necessary to } \\
\text { read so much text in Group LINE each day even though most of those } \\
\text { texts are not involved in me. }\end{array}$ & \\
\hline PR6 & $\begin{array}{l}\text { I feel that I spend time too much for using LINE in daily which has } \\
\text { negative effects to my study or job. Furthermore, I do not pay attention } \\
\text { to people who I am closed with because I heavily use this application. }\end{array}$ & \\
\hline \multicolumn{3}{|c|}{ Enjoyment of LINE Activity (ELA) } \\
\hline ELA1 & $\begin{array}{l}\text { I enjoy contacting with friends via LINE App because it is so fast and it is } \\
\text { not necessary to connect to high internet speed. }\end{array}$ & \multirow{6}{*}{ Depth interview } \\
\hline ELA2 & $\begin{array}{l}\text { I enjoy sending stickers to my friends via LINE App for my emotional } \\
\text { expression via this application. }\end{array}$ & \\
\hline ELA3 & $\begin{array}{l}\text { I am enjoyable by using TIME LINE for posting myself stories, and there } \\
\text { are many friends come to post their comments and send stickers for my } \\
\text { story. }\end{array}$ & \\
\hline ELA4 & I feel fun to follow up news in Group LINE. & \\
\hline ELA5 & $\begin{array}{l}\text { I enjoy calling free via LINE App. It is free of charge and unlimited time } \\
\text { of calling out. }\end{array}$ & \\
\hline ELA6 & $\begin{array}{l}\text { I enjoy playing in the TimeLINE in LINE App because its functions are } \\
\text { similar to Facebook. I can update story every time by posting pictures, } \\
\text { links, clips, and etc. }\end{array}$ & \\
\hline \multicolumn{3}{|c|}{ Perceived Value of LINE } \\
\hline $\begin{array}{l}\text { PVL1 } \\
\text { PVL2 }\end{array}$ & $\begin{array}{l}\text { LINE application is fast to use to compare to other similar applications. } \\
\text { LINE application help me contact to all or almost people who I have } \\
\text { known. }\end{array}$ & $\begin{array}{l}\text { Chang et al. } \\
\text { (2016); Teas } \\
\text { and Agarwal } \\
(2000) ; \\
\text { Zeithaml, (1988) }\end{array}$ \\
\hline PVL3 & $\begin{array}{l}\text { I can use a LINE application to send my docs to my friends or other } \\
\text { people via PC computer or smartphone instead of by sending docs by } \\
\text { email. It is so very convenient. }\end{array}$ & \multirow{3}{*}{ Depth interview } \\
\hline PVL4 & $\begin{array}{l}\text { GroupLINE makes me feel I am a part of the group. I can follow up my } \\
\text { group members movement accurately. }\end{array}$ & \\
\hline PVL5 & $\begin{array}{l}\text { I can save money a lot for monthly phone bill by using free call in LINE } \\
\text { application. }\end{array}$ & \\
\hline
\end{tabular}


After describing the chacteristics of respondents using descriptive statistical methods, the questionnaires were analyzed using the partial least square-structural equation modeling (PLS-SEM). This multivariate analysis technique is acknowledged as an increasingly popular one with researchers (Hair, Ringle, \& Sarstedt, 2011; Toe, Tan, Ooi, \& Lin, 2015).

\section{Results}

The questionnaire involved in this study was distributed over the period March - April 2018. The method of distribution utilized an online questionnaire platform called 'Qualtrics'. This website allowed the researchers to create a questionnaire and to post a link to it on various LINE pages. LINE users who read the link were invited to complete the questionnaire and participate in the study. Two hundred and twenty-three people responded to the links. The completed reponses were checked for usability and reliability and as a result of that process only one hundred and ninety were deemed to be complete and valid for analysis. The demographic information of the respondents who were cleared is shown in Table 2. PLS-SEM requires a sample size at least ten times the highest number of paths directed at any one latent construct in the structural model (Hair et al., 2011). As, in this study, there are three paths from PC, PR and ELA indirected and directed at PVL (see Figure 1), the sample size should exceed 30 . The sample size of this study is 190, so it more than satisfies the requirements of PLS-SEM.

Table 2: Demographics of Respondents

\begin{tabular}{llcc}
\hline & Demographics & $\begin{array}{c}\text { Number of } \\
\text { responses }\end{array}$ & $\begin{array}{c}\text { Percentage of } \\
\text { responses (\%) }\end{array}$ \\
\hline Gender & Male & 120 & 63.2 \\
Age & Female & 70 & 36.8 \\
& $<20$ years old & 27 & 14.2 \\
& $20-30$ years old & 63.7 \\
Education & $31-40$ years old & 121 & 14.7 \\
& $>40$ years old & 28 & 7.4 \\
Experience of LINE usage & Bachelor degree & 14 & 41.0 \\
& Bachelor degree & 78 & 52.1 \\
& Master degree & 5.8 \\
& Doctoral degree & 11 & 1.1 \\
& $<1$ year & 2 & 0.5 \\
& 1 year & 1 & 5.3 \\
& 2 years & 10 & 12.6 \\
& 3 years & 24 & 25.3 \\
Daily LINE usage & 4 years & 48 & 20.0 \\
& 5 years & 38 & 33.7 \\
& $>5$ years & 64 & 2.6 \\
& Every 10 minutes & 5 & 17.4
\end{tabular}




\begin{tabular}{lll} 
Every 2 hours & 20 & 10.5 \\
Every half day & 20 & 10.5 \\
Once a day & 34 & 17.9 \\
\hline
\end{tabular}

The undimensionality of the model was tested using PLS-SEM analysis. Undimensionality is determined by using Cronbach's alpha (a) and composite reliability (CR). If a block has $\alpha$ and $\mathrm{CR}$ above 0.70 then it was deemed to be unidimensional (Tenenhaus, Vinzi, Chatelin, \& Lauro, 2005). Table 3 shows the values obtained for this experiment were higher than the required minimum. The Cronbach's alpha result was between 0.74 to 0.84 and $C R$ was between 0.85 to 0.89 .

In Table 3 the measurement model estimations, outer weights, loadings and average variance extracted (AVE) measures can also be seen. An outer loading (represented by the loadings of reflective manifest variables and their related latent vaiables), of above 0.70 indicates an individual item's reliability (Hulland, 1999). For this experiment, results between 0.70 to 0.92 were obtained and therefore exceded the minimum 0.70 required.

Table 3: The Results from the Measurement Model Estimation (Weight, Loading, CR Value, Cronbach's $\alpha$, and AVE)

\begin{tabular}{|c|c|c|c|c|c|c|}
\hline Latent variable & $\begin{array}{l}\text { Manifest } \\
\text { variable }\end{array}$ & $\begin{array}{c}\text { Outer } \\
\text { weight }\end{array}$ & $\begin{array}{c}\text { Outer } \\
\text { loading }\end{array}$ & $\begin{array}{c}\text { CR } \\
\text { value }\end{array}$ & $\begin{array}{l}\text { Cronbach's } \\
\text { alpha }(\alpha)\end{array}$ & AVE \\
\hline \multirow{4}{*}{ Privacy concerns (PC) } & PC1 & 0.28 & 0.78 & 0.89 & 0.84 & 0.68 \\
\hline & PC2 & 0.22 & 0.77 & & & \\
\hline & PC3 & 0.34 & 0.86 & & & \\
\hline & PC4 & 0.37 & 0.85 & & & \\
\hline \multirow[t]{3}{*}{ Perceived risk (PR) } & PR1 & 0.48 & 0.92 & 0.85 & 0.74 & 0.66 \\
\hline & PR2 & 0.35 & 0.86 & & & \\
\hline & PR3 & 0.39 & 0.77 & & & \\
\hline \multirow{5}{*}{$\begin{array}{l}\text { Enjoyment of LINE } \\
\text { activity (ELA) }\end{array}$} & ELA2 & 0.23 & 0.72 & 0.88 & 0.83 & 0.60 \\
\hline & ELA3 & 0.21 & 0.73 & & & \\
\hline & ELA4 & 0.28 & 0.77 & & & \\
\hline & ELA5 & 0.28 & 0.70 & & & \\
\hline & ELA6 & 0.29 & 0.70 & & & \\
\hline \multirow{4}{*}{$\begin{array}{l}\text { Perceived value of LINE } \\
\text { (PVL) }\end{array}$} & PVL2 & 0.29 & 0.82 & 0.87 & 0.81 & 0.63 \\
\hline & PVL3 & 0.33 & 0.85 & & & \\
\hline & PVL4 & 0.34 & 0.91 & & & \\
\hline & PVL5 & 0.29 & 0.73 & & & \\
\hline
\end{tabular}

The convergent construct validity was tested by the average variance extracted (AVE) which ranged between 0.60 to 0.68 exceding the minimum of 0.5 suggested by Fornell and Larcker (1981). The recommendations of Fornell and Larcker (1981) were also used to test discriminant validity. Fornell and Larcker (1981) recommend the AVE square root for individual constructs should be higher than the estimated correlation between the construct and other constructs. For this experiment the square root of AVE was 
calculated for each construct (Table 4, diagonal elements) and was found to be higher than the correlation of the construct with other constructs (Table 4, off-diagonal elements).

Table 4: Inter-Construct Correlations and Square Root of AVE Measure

\begin{tabular}{lllll}
\hline & PC & PR & ELA & PVL \\
\hline PC $^{1}$ & 0.82 & & & \\
PR $^{1}$ & 0.41 & 0.81 & & \\
ELA $^{1}$ & 0.13 & 0.09 & 0.77 & 0.79 \\
PVL $^{1}$ & 0.20 & 0.09 & 0.70 & \\
\hline
\end{tabular}

1 PC: privacy concerns; PR: perceived risk; ELA: enjoyment of LINE activity; PVL: perceived value of LINE. The diagonal element, which shows the square root of AVE on each construct, is in Italics font.

Once the measurement model had been validated, the next step was to study the relationship between the latent vairaibles to estimate the structural model. The path coefficients for the endogenenous latent variables and R-squares are shown in Figure 2.

Figure 2 also illustrates the empirical results (1) LINE users' PVL associates significantly with ELA ( $\beta=0.76, t=12$. 3966), but does not significantly associate with PR $(\beta=0.026, t=0.347)$; (2) LINE users' ELA does not significantly associates with PR ( $\beta=$ $0.040, \quad t=0.271)$ and $P C(\beta=0.117, t=0.913)$; and (3) LINE users' PR associates significantly with $P C(\beta=0.407, t=5.027)$. Hypotheses $H 1$ and $H 5$ are supported by these findings.

Figure 2: Empirical study results

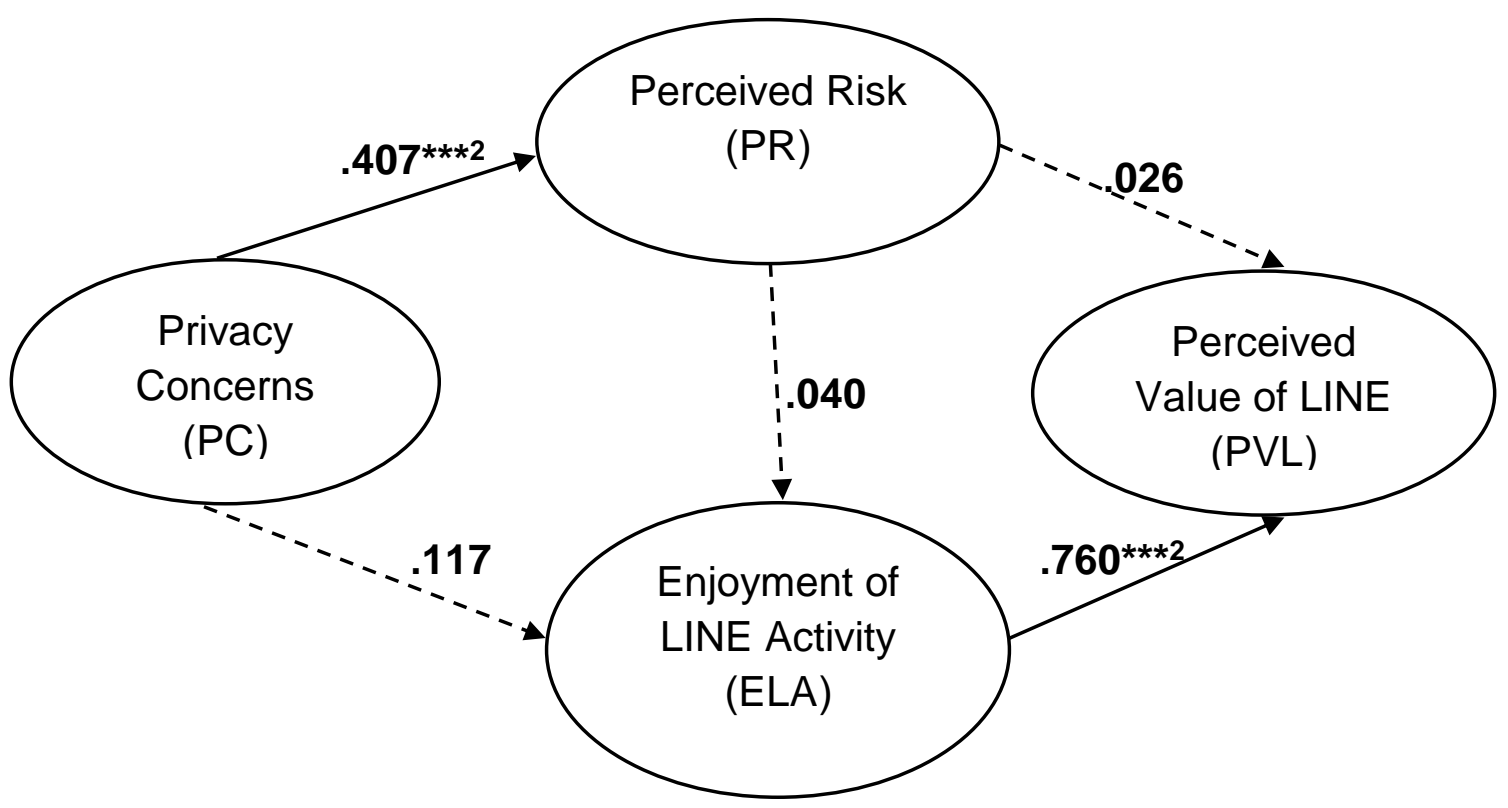

$2{ }^{*} p<0.05,{ }^{* *}: p<0.01,{ }^{* * *}: p<0.001$ 


\section{Discussion}

This study demonstrates that users' ELA can enhance users' PVL (in terms of path coefficients and statistic significance), while ELA is not influenced by PC and PR. To consider each item from the value of the outer loadings it was found that LINE users feel it is fun to follow-up news in groups using LINE (0.77), they enjoy using the timeline function for posting their own stories and then to see the many comments and stickers posted by their friends about that story $(0.73)$. Users also enjoy sending stickers to their friends as a method of sharing their mood via this application (0.72). This particular finding is in line with prior research that found enjoyment plays an important role in producing positive value perceptions towards technology (Fagan et al., 2008; Venkatesh, 2000; Venkatesh et al., 2003). The pleasure-oriented information system environment was influenced by enjoyment. Furthermore, perceived enjoyment is associated with perceived value in a pleasure-oriented environment (Chang et al., 2016; Lee et al., 2013; Venkatesh et al., 2012).

LINE application users' PVL, reveals how customers appreciate the ability to communicate in groups using LINE as this function allows them feel a part of a social community. They can follow-up the group members' movements regularly (0.92). Similarly, they think that LINE application helps them contact to either all, or most of the people, whom they know (0.82). On-line communities, (such as those formed in the groups function using the LINE application) are described by Rheingold (2001) as virtual communities. A virtual community is one that is geographically and physically separated, but whose members communicate with each other via the internet. Members can comment on discussions, give advice to each other and work together in a collaborative manner. Such online communities have the capacity to make members feel they belong, that they have a home with an invisible family of friends. In order to belong to such a community the requirements are that members have a handheld device, an internet connection, subscribe to the same application and have been invited into the group by one of that group (Ridings \& David, 2006; Wang, Chung, Park, McLaughlin, \& Fulk, 2012). Additionally, as the result of this study show in item PVL3, customers can use the LINE application to send their documents to friends or other people via a personal computer or smartphone instead of sending them by email. Participants found this fuction to be very convenient $(0.85)$.

This research also confirms that LINE application users' PR is significantly associated with PC. This significant relationship is associated with prior research (Chang et al., 2016; Ofori et al., 2015; Slyke et al., 2006; Zhou \& Li, 2014). For users' PC, the results show users are worried that their private and personal data on the LINE application is not safe or secure, nor that their privacy will be intruded upon by other unauthorized and unknown people $(P C 3=0.86)$. They are concerned that using the LINE application will reveal their 
private information $(P C 4=0.85)$. Lankton and McKnight $(2011)$ state that the extent of the trust a user feels towards the provider of a particular application and their perceptions of the protection they are afforded by that company, combine to constitute the the privacy concerns of the smartphone, social network services. The fear that data will be lost, misused or accessed by someone they do not know makes users worry and this issue can determine the PR for LINE (Zhou, 2011). For PR, the security mechanism provided by the LINE application is not enough to sufficiently protect users privacy (PR1 $=0.92)$. Overall, users think it is more-or-less unsafe to use the LINE application (PR2 $=0.86$ ). Some LINE customers have not only become reluctant to reveal personal information on the application, but have closed their accounts as a way to protest against the insecure and unsafe LINE management of personal information. With the negative effects of PC and PR, it is conceivable that LINE application users might cease to enjoy using the LINE application. However, this finding shows that both LINE application users' PC and PR did not influence ELA and PVL (Chang et al., 2016). One possible explanation for these insignificant relationships might be because LINE users who really enjoy using LINE application activities and thus ignore the potential negative effects of PC and PR (Chang et al., 2016).

\section{Conclusion and Recommendations}

The influence of ELA, PR and PC on the PVL of LINE application's users was investigated with five hypotheses. By analyizing the data collected in the experiment the study was able to demonstrate that LINE application users' ELA can enhance PVL but that ELA is not influenced by either PC or PR. Furthermore, the analysis revealed that LINE application users' PR was significantly associated with PC and this finding might explain why the users of LINE perceive value in the application. Perceived enjoyment was identified as playing an important part in creating positive value perceptions towards the technology. Enjoyment also played an important role in the pleasure-orientated information system environment. However, LINE application users' PC and PR did not significantly influence ELA and PVL and this could be due to users enjoying the activities available on LINE and that enjoyment encouraged them to ignore any of the potential negative effects from PC and PR.

This study is based upon the results of examining the perceptions of LINE's value by users in Bangkok, Thailand and thus the results might not apply to LINE users in other countires where customs, lifestyles and habits might differ from those in Bangkok. Indeed, the differences between perceptions of value for LINE from users in different countires or different cultures could be a very interesting topic for further research. Further research might also explore how to build perceived value in the LINE application 
for various groups of users such as young people, elderly citizens, males, females, and middle or working class socioeconomic groups. By expanding the scope of research to include a wider cross section of users the findings would be more generalizable.

\section{References}

Chang, S. E., Liu, Y. A. \& Lin, S. (2015). Exploring privacy and trust for employee monitoring. Industrial Management \& Data Systems, 115(12), 88-106.

Chang, S. E., Shen, W. C. \& Liu, A. Y. (2016). Why mobile users trust smartphone social networking services? A PLS-SEM approach. Journal of Business Research, 69, 4890-4896.

China Economic Review, (2013, January 9). Taiwan messaging app Line looks to increase growth in 2013. China Economic Review. Retrieved from: http://www.chinaeconomicreview.com/taiwan-messagingapp-line-looks-increase-growth-2013

Dinev, T. \& Hart, P. (2006a). An extended privacy calculus model for E-commerce transactions. Information Systems Research, 17(1), 61-80.

Dinev, T. \& Hart, P. (2006b). Internet privacy concerns and social awareness as determinants of intention to transact. International Journal of Electronic Commerce, 10(2), 7-29.

Dodds, W. B., Monroe, K. B. \& Grewal, D. (1991). Effects of price, brand, and store information on buyers' product evaluations. Journal of Marketing Research, 28(3), 307-319.

Dowling, G. R. \& Staelin, R. (1994). A model of perceived risk and intended risk-handling activity. Journal of Consumer Research, 21(1), 119-134.

Fagan, M. H., Neill, S. \& Wooldridge, B. R. (2008). Exploring the intention to use computers: An empirical investigation of the role of intrinsic motivation, extrinsic motivation, and perceived ease of use. Journal of Computer Information Systems, 48(3), 31-37.

Fornell, C. \& Larcker, D. F. (1981). Evaluating structural equation models with unobservable variables and measurement error. Journal of Marketing Research, 18(1), 39-50.

Hair, J. F., Ringle, C. M. \& Sarstedt, M. (2011). PLS-SEM: Indeed a silver bullet. Journal of Marketing Theory and Practice, 19(2), 139-152. 
Hsiao, C. H., Chang, J. J. \& Tang, K. Y. (2016). Exploring the influential factors in continuance usage of mobile social Apps: Satisfaction, habit, and customer value perspectives. Telematics and Informatics, 33, 342-355.

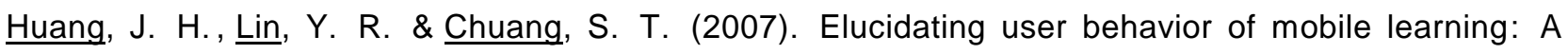
perspective of the extended technology acceptance model. The Electronic Library, 25(5), 585598.

Hulland, J. S. (1999). Use of partial least squares (PLS) in strategic management research: A review of four recent studies. Strategic Management Journal, 20(2), 195-204.

Lankton, N. \& McKnight, D. H. (2011). What does it mean to trust Facebook? Examining technology and interpersonal trust beliefs. The Data Base for Advances in Information System, 42(2), 32-54.

Lee, H. -G., Chung, S. \& Lee, W. H. (2013). Presence in virtual golf simulators: The effects of presence on perceived enjoyment, perceived value, and behavioral intention. NewMedia \& Society, 15(6), 930946.

LINE, (2014). LINE surpasses 400 million registered users. (2014, $2^{\text {nd }}$ April). LINE Corporation. Retrieved from; http://linecorp.com/en/press/2014/0402714.

Malhotra, N. K., Kim, S. S. \& Agarwal, J. (2004). Internet users' information privacy concerns (IUIPC): The construct, the scale, and a causal model. Information Systems Research, 15(4), 336-355.

McKnight, D. H., Choudhury, V. \& Kacmar, C. (2002). The impact of initial consumer trust on intentions to transact with a web site; a trust building model. Journal of Strategic Information Systems, 11, 297323.

Meredith, D. P. (2017). A blended learning instructional model using instant messaging to increase engagement and improve attitudes of Thai EFL communication arts students. A dissertation (yet to be published) submitted to the Graduate Degree Programme in Teaching and Technology, Graduate School of eLearning, Assumption University of Thailand in partial fulfilment of the requirements for the degree of Doctor of Philosophy.

Nofer, M., Hinz, O., Muntermann, J. \& Robnagel, H. ((2014). The economic impact of privacy violations and security breaches. Business \& Information Systems Engineering, 6(6), 339-348.

Ofori, K. S., Larbi-Siaw, O., Fianu, E. Gladjah, R. E. \& Boateng, E. O. Y. (2015). Factors influencing the continuance use of mobile social media: The effect of privacy concerns. Journal of Cyber Security, 4 , 105-124. 
Purnell. N. (2014, June 19th). Messaging apps vie for dominance in Southeast Asia. The Wall Street Journal. Retrieved from; www.online.wsj.com

Reyburn, S. (2013). Messaging app Line surpasses 100m users in 19 months. January 18, 2013. Retrieved from; http://www.insidemobileapps.com/2013/01/18/messaging-app-line-surpasses-100m-users-in19-months/

Rheingold, H. (2001). The Virtual Community: Homesteading on the Electronic Frontier. New York, NY: Harper Perennial.

Ridings, C. M., \& David, G. (2006). Virtual Community Attraction: Why People Hang Out Online. Journal of Computer-Mediated Communication, 10(1), 00.

Sheppard, B. H. \& Sherman, D. M. (1998). The grammars of trust: A model and general implications. The Academy of Management Review, 23(3), 422-437.

Shin, D. H. (2010). The effects of trust, security and privacy in social networking: A security-based approach to understand the pattern of adoption. Interacting with Computers, 22(5), 428-438.

Slyke, C. V., Shim, J., Johnson, R. \& Jiang, J. (2006). Concern for information privacy and online consumer purchasing. Journal of the Association for Information Systems, 7(6), 415-444.

Tan, X. \& Qin, L. (2012). Impact of privacy concern in social networking web sites. Internet Research, 22(2), 211-233.

Teas, R. K. \& Agarwal, S. (2000). The effects of extrinsic product cues on consumers' perceptions of quality, sacrifice and value. Journal of the Academy of Marketing Science, 28(2), 278-290.

Tenenhaus, M., Vinzi, V. E., Chatelin, Y. M. \& Lauro, C. (2005). PLS path modeling. Computational Statistics and Data Analysis, 48(1), 159-205.

Toe, A. C., Tan, G. W. H., Ooi, K. B. \& Lin, B. (2015). Why consumers adopt mobile payment? A partial least squares structural equation modeling (PLS-SEM) approach. International Journal of Mobile Communications, 13(5), 478-497.

Van De Bogart, W. \& Wichadee, S. (2015). Exploring students' intention to use LINE for academic purposes base on technology acceptance model. International Review of Research in Open and Distributed Learning, 16(3), 65-85.

Venkatesh, V. (2000). Determinants of perceived ease of use: integrating control, intrinsic motivation, and emotion into the technology acceptance model. Information System Research, 11(4), 342-365. 
Venkatesh, V., Morris, M. G., Davis, G. B. \& Davis, F. D. (2003). User acceptance of information technology: Toward a unified view. MIS Quarterly, 27(3), 425-478.

Venkatesh, V., Thong, J. \& Xu, X. (2012). Consumer acceptance and use of information technology: Extending the unified theory of acceptance and use of technology. MIS Quarterly, 36(1), 157-178.

Wang, H., Chung, J. E., Park, N., McLaughlin, M. L. \& Fulk, J. (2012). Understanding on LINE community participation: A technology acceptance perspective. Communication Research, 39(6), 781-801.

Xu, H., Dinev, T., Smith, J. \& Hart, P. (2011). Information privacy concerns: Linking individual perceptions with institutional privacy assurances. Journal of the Association for Information Systems, 12(12), 798824.

Zeithaml, V. A. (1988). Consumer perceptions of price, quality, and value: A means-end model and synthesis of evidence. Journal of Marketing, 52(3), 2-22.

Zhou, T. \& Li, H. (2014). Understanding mobile SNS continuance usage in China from the perspectives of social influence and privacy concern. Computers in Human Behavior, 37, 283-289.

Zhou, T. (2011). Understanding onLINE community user participation: a social influence perspective. Internet Research, 21(1), 67-81. 